\title{
Analysis of torque ripple reduction in a segmented-rotor synchronous reluctance machine by optimal currents
}

\author{
Hailong WU, Daniel DEPERNET \\ Univ. Bourgogne Franche-Comté, UTBM \\ FEMTO-ST Institute, Energy Department \\ FCLAB Research Federation (FR CNRS 3539) \\ 90010 Belfort Cedex, France
}

\author{
Vincent LANFRANCHI \\ Laboratoire d'Electromécanique de Compiègne \\ Sorbonne Université, Université de Technologie de \\ Compiègne \\ 60203 Compiègne Cedex, France
}

\begin{abstract}
The research about synchronous reluctance machine (SynRM) has been revived in the last decades because of its advantages. But the torque ripple limits the performances of SynRM. Based on the feature of SynRM, this paper proposes a new method in order to calculate the optimal currents which contain many harmonics. Based on the proposed torque function, this method does not use the specific stator inductances to reduce torque ripple. Then, the compensated torques by supplying different orders of optimal currents are compared and analyzed. Besides, the influence of magnetic saturation on the proposed method is also studied. Thirdly, the added current harmonics could increase the losses of the machine. Therefore, the copper losses of the machine are also analyzed. It has shown that the proposed approach can decrease torque ripple effectively.
\end{abstract}

Keywords: Inductance harmonics; Synchronous reluctance machine; Torque ripple; Optimal currents; Saturation; Copper losses

\section{Introduction}

Synchronous reluctance machine has been paid much more attentions from the last decades because of its various advantages. For example, its mechanical structure, no-winding rotor, makes it robust and simple. Its feature of having no permanent magnets reduces the cost greatly and makes it operate at high speed and at high temperature. However, compared with induction machine and permanent magnet synchronous machine, several factors such as low power factor and higher torque ripple also limit its wide applications [1].

Many papers aiming to improve the performances of SynRM have been published. When it comes to torque ripple, many articles study and minimize torque ripple by various methods [3]-[8].The special structure of SynRM makes the inductances of d-axis and q-axis $\left(L_{\mathrm{d}}\right.$ and $\left.L_{\mathrm{q}}\right)$ change periodically with the rotor position even when there is no saturation. So [3] expresses $L_{\mathrm{d}}$ and $L_{\mathrm{q}}$ of a SynRM with flux barriers rotor as a function of rotor's position. The expressions are used to reduce torque ripple by optimizing the design parameters. Other results of reducing torque ripple by various designs such as optimal rotor shapes and various barriers' dimensions can also be found in [4]-[8]. However, as stated in [3], the flux ripple of SynRM can be reduced instead of being eliminated. It means that torque ripple could be decreased effectively by good design, but torque ripple can still exist.

To reduce the torque ripple further, control method are applied [9]-[12]. Because of the salient structure of SynRM, the stator inductances contain many harmonics. As a result, non-sinusoidal currents can be supplied as the optimal currents for SynRM to produce less torque ripple and get better performances. Several methods have 
been proposed to obtain the optimal currents. The authors [9] used the winding function method to model the nosinusoidal stator windings to get the inductances of stator. They also calculated the optimal currents with the inductances and designed vector controllers to reduce torque ripple of SynRM. Besides, finite element method (FEM) was applied to get the inductances of stator in [10]; the optimal currents were obtained by Lagrange optimization and artificial neural networks. Neural controllers were also designed to decrease torque ripple successfully. However, in the above studies, the self-inductances and mutual inductances of stator [13] should be obtained firstly which needs much effort. Besides, the harmonics of the inductances are just limited to the 3rd harmonic which may lead to insufficient optimal currents and could give different results. Therefore, there still exist several questions. What are the effects of different currents' harmonics? How to define the optimal order of currents' harmonics which can minimize torque ripple sufficiently? It still needs further research and more analysis. Moreover, saturation can affect the torque ripple reduction seriously because the compensation of torque ripple by control strategy requires the inductances information. But its influence on torque ripple reduction has been little studied.

In this paper, a method which does not need to obtain the stator inductances is proposed to reduce torque ripple. The suggested method [14] is realized by defining the torque function which contains all the inductances' information and can be obtained easily. As a result, the optimal currents calculated by the torque function contain enough harmonics to decrease torque ripple. The compensated torque is analyzed in order to define the optimal order of currents' harmonics. Besides, saturation which can deteriorate the proposed approach is studied to give a deep understanding of the proposed method. At last, the currents harmonics could increase the losses. The Joule losses increased by different current harmonics are also analyzed. The paper is organized as follows. The second part presents the general torque equation and introduces the proposed method. The third part gives the results and analysis of torque ripple reduction. The fourth part studies, explains and analyzes the influence of saturation. In the fifth part, copper losses are presented and analyzed. At last, the conclusion summarizes the article.

\section{The proposed method to minimize torque ripple}

\subsection{The general torque expression}

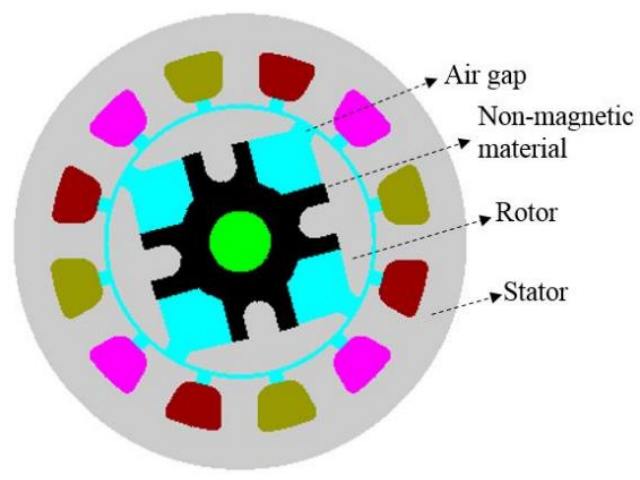

Fig.1 The studied SynRM

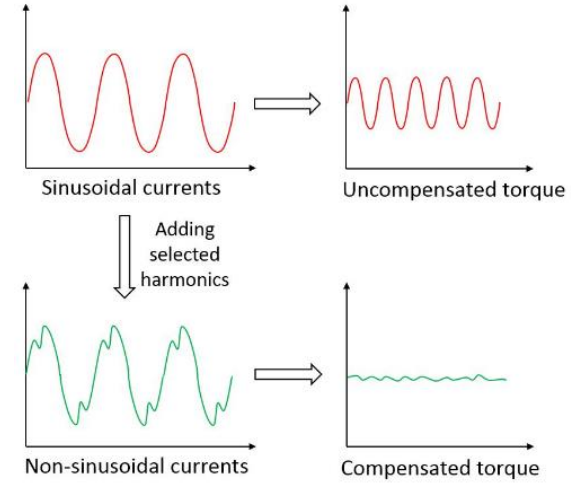

Fig.2 The strategy of torque ripple reduction

The studied synchronous reluctance machine (SynRM) whose rotor is segmented is shown in Fig.1. For the application of an e-Clutch, this SynRM is selected and studied. Further information can be found in [15][16].

As mentioned above, torque ripple in SynRM can be compensated by the optimal non-sinusoidal currents which is shown in Fig.2 . If the SynRM is supplied by sinusoidal currents, the produced torque is pulsating. However, adding some proper currents harmonics to the sinusoidal currents could reduce electromagnetic torque ripple greatly. So how to define the optimal currents is very important. There are two methods to get the proper 
currents harmonics. The first method [17][18] analyzes the torque ripple to find the severe torque harmonics. Based on these harmonics, the corresponding currents harmonics are defined and added to the sinusoidal currents to get the optimal currents and at last the optimal currents are applied to reduce torque ripple. This method needs much effort to analyze the torque harmonics and define the currents harmonics. The second approach [10] [19] calculates the optimal currents which contain all the currents harmonics directly. However, it needs to calculate the inductances of stator which can also need much effort. In this paper, the proposed method which is easier to be applied is similar to the second method, but it does not require the stator inductances.

At first, the Eq. (2) presents the electromagnetic torque which is calculated by co-energy as shown by Eq. (1). The matrix of stator inductances which contains harmonics is introduced by Eq. (3). The parameter $k$ represents the order of the inductances' harmonics. It's defined in this paper that when $k=2$ the harmonic is second and $k=4$ means the fourth harmonic, and so on.

The co-energy can be expressed as

$$
W\left(I, \theta_{m}\right)=\frac{1}{2} \sum_{j=1}^{3} \sum_{s=1}^{3} L_{j s}\left(\theta_{m}\right) I_{j} I_{s}
$$

Where $j$ and $s$ represent the number of three stator windings; $L_{j s}$ is the corresponding self-inductance and mutual inductance of stator windings; $I$ is the stator current and $\theta_{m}$ is the electrical rotor position.

Then the electrical torque can be calculated by

$$
\begin{aligned}
T_{e}=\frac{\partial W\left(I, \theta_{m}\right)}{\partial \theta_{m}}= & P \frac{\partial W(I, \theta)}{\partial \theta}=\frac{P}{2} \sum_{j=1}^{3} \sum_{s=1}^{3} I_{j} I_{s} \frac{\partial L_{j s}(\theta)}{\partial \theta} \\
\boldsymbol{L}_{j s}(\theta)= & {\left[\begin{array}{lll}
L_{1} & L_{1}^{\prime} & L_{1}^{\prime} \\
L_{1}^{\prime} & L_{1} & L_{1}^{\prime} \\
L_{1}^{\prime} & L_{1}^{\prime} & L_{1}
\end{array}\right]+} \\
& {\left[\begin{array}{ccc}
\sum_{k=2,4, \ldots} L_{k} \cos (k \theta) & \sum_{k=2,4, \ldots} L_{k}^{\prime} \cos \left(k\left(\theta+\frac{2 \pi}{3}\right)\right) & \sum_{k=2,4, \ldots} L_{k}^{\prime} \cos \left(k\left(\theta-\frac{2 \pi}{3}\right)\right) \\
\sum_{k=2,4, \ldots} L_{k}^{\prime} \cos \left(k\left(\theta+\frac{2 \pi}{3}\right)\right) & \sum_{k=2,4, \ldots} L_{k} \cos \left(k\left(\theta-\frac{2 \pi}{3}\right)\right) & \sum_{k=2,4, \ldots} L_{k}^{\prime} \cos (k \theta) \\
\sum_{k=2,4, \ldots} L_{k}^{\prime} \cos \left(k\left(\theta-\frac{2 \pi}{3}\right)\right) & \sum_{k=2,4, \ldots} L_{k}^{\prime} \cos (k \theta) & \sum_{k=2,4, \ldots} L_{k} \cos \left(k\left(\theta+\frac{2 \pi}{3}\right)\right)
\end{array}\right] }
\end{aligned}
$$

Where $P$ is the number of pole paires; $L_{1}$ and $L_{1}^{\prime}$ are the constant components of self-inductances and mutualinductances; $L_{\mathrm{k}}$ and $L_{k}^{\prime}$ are the amplitudes of $k$ th self-inductance and $k$ th mutual-inductance; $\theta$ is the electrical rotor position.

On the other hand, the frequently used torque expression can be presented by Eq. (4) [20] supposing that the stator inductances only have the constant component and the second harmonic.

$$
T_{e}=\frac{3}{2} P\left(L_{d}-L_{q}\right) I_{d 23} I_{q 23}
$$

These currents $I_{\mathrm{d} 23}$ and $I_{\mathrm{q} 23}$ are calculated by power variant Clark and Park transformation. This equation is usually applied to calculate the average torque and to control the synchronous reluctance machine [20][21]. However, with more stator inductance harmonics in SynRM, this equation cannot be used to calculate the instantaneous electromagnetic torque. It cannot depict the variation of torque correctly which implies that the optimal currents cannot be obtained to reduce the torque ripple.

The synchronous reluctance machine is usually controlled by regulating d-axis and q-axis currents. Hence, the torque Eq. (2) can be rewritten [22] as

$$
T_{e}=\frac{P}{2} \boldsymbol{I}_{a b c}^{T} \frac{\partial \boldsymbol{L}_{j s}(\theta)}{\partial \theta} \boldsymbol{I}_{a b c}=\frac{P}{2} \boldsymbol{I}_{d q}^{T} \boldsymbol{C}_{32}(\theta) \frac{\partial \boldsymbol{L}_{j s}(\theta)}{\partial \theta} \boldsymbol{C}_{32}^{T}(\theta) \boldsymbol{I}_{d q}
$$


In Eq. (5), the currents of d-axis and q-axis are calculated from stator currents

$\boldsymbol{I}_{d q}=\boldsymbol{C}_{32}(\theta) \boldsymbol{I}_{a b c}$

The power invariant transformation matrix [23] and the stator currents are represented by

$$
\begin{aligned}
& \boldsymbol{C}_{32}(\theta)=\sqrt{2 / 3}\left(\begin{array}{ccc}
\cos \theta & \cos \left(\theta-\frac{2 \pi}{3}\right) & \cos \left(\theta-\frac{4 \pi}{3}\right) \\
-\sin \theta & -\sin \left(\theta-\frac{2 \pi}{3}\right) & -\sin \left(\theta-\frac{4 \pi}{3}\right)
\end{array}\right) \\
& \boldsymbol{I}_{a b c}=\left[\begin{array}{c}
I_{m} \cos (\theta+\beta) \\
I_{m} \cos \left(\theta-\frac{2 \pi}{3}+\beta\right) \\
I_{m} \cos \left(\theta-\frac{4 \pi}{3}+\beta\right)
\end{array}\right]
\end{aligned}
$$

Where $I_{\mathrm{m}}$ is the maximal value of stator current and $\beta$ is the current angle which can represent the relation between $I_{\mathrm{d}}$ and $I_{\mathrm{q}}$

$$
K_{d q}=\tan \beta=\frac{I_{q}}{I_{d}}
$$

Besides, replacing $I_{\mathrm{q}}$ in Eq. (5) by Eq. (9), the torque can be expressed by

$$
T_{e}=\frac{P}{2}\left[\begin{array}{ll}
1 & K_{d q}
\end{array}\right] \boldsymbol{C}_{32} \frac{\partial \boldsymbol{L}(\theta)}{\partial \theta} \boldsymbol{C}_{32}^{T}\left[\begin{array}{c}
1 \\
K_{d q}
\end{array}\right] I_{d}^{2}=K_{t}(\theta) I_{d}^{2}
$$

With $K_{t}(\theta)=\frac{P}{2}\left[\begin{array}{ll}1 & K_{d q}\end{array}\right] \boldsymbol{C}_{32} \frac{\partial \boldsymbol{L}(\theta)}{\partial \theta} \boldsymbol{C}_{32}^{T}\left[\begin{array}{c}1 \\ K_{d q}\end{array}\right]$

The torque function $K_{\mathrm{t}}(\theta)$ is defined as the function of the stator inductances and the current angle. On the other hand, $K_{\mathrm{t}}(\theta)$ can also be calculated by

$$
K_{t}(\theta)=\frac{T_{e}}{I_{d}^{2}}
$$

If the sinusoidal currents are supplied into the SynRM, the electromagnetic torque can be measured. As a result, it does not use the stator inductances to calculate $K_{\mathrm{t}}(\theta)$. Furthermore, in this paper, it's preferable to apply the maximum torque per ampere (MTPA) control strategy [24][25] which means $I_{\mathrm{d}}$ equals $I_{\mathrm{q}}$ and the efficiency of SynRM is maximal. Namely, $\beta$ is $45^{\circ}$ and $K_{\mathrm{dq}}$ equals 1 .

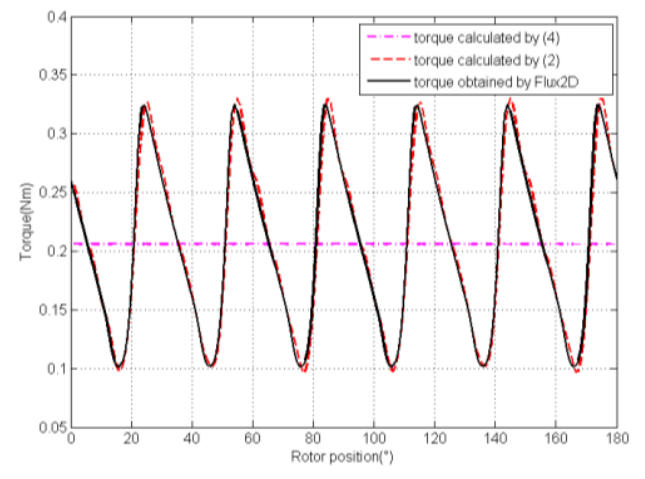

Fig. 3 Torques obtained by Flux 2D and calculations

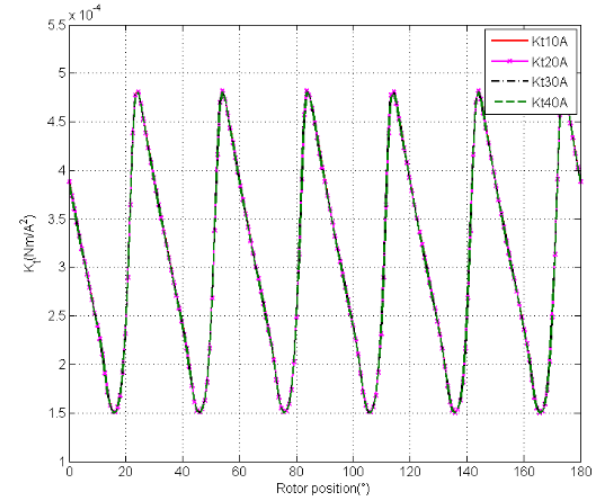

Fig. 4 The torque function $K_{\mathrm{t}}(\theta)$ for different currents

Simulations have been implemented in Flux 2D to verify the general torque equation Eq. (2) and Eq. (10). The maximal value of current is 30A $\left(I_{\mathrm{m}}\right)$. As shown in Fig. 3, torque ripple of the studied SynRM is severe and it should be minimized. What's more, the torque obtained by Eq. (2) is very close to the torque exported from Flux 2D. However, the torque calculated by Eq. (4) is constant. Therefore, the general torque expression which is same to equation (10) is confirmed and can be applied to represent the torque ripple and to reduce torque ripple. 
Besides, $K_{\mathrm{t}}(\theta)$ is calculated for different currents $\left(I_{\mathrm{m}}=10 \mathrm{~A}, 20 \mathrm{~A}, 30 \mathrm{~A}\right.$ and $\left.40 \mathrm{~A}\right)$, but for the same current angle. According to Fig. 4, it can be seen that the torque function $K_{\mathrm{t}}(\theta)$ is a function of the rotor position and for different stator currents, it is independent of stator current $\left(I_{\mathrm{m}}\right)$ when saturation is neglected. If the current angle is selected as the optimal value to get maximum torque and if the saturation can be negligible, the relation between electromagnetic torque and stator current is fixed. Therefore, the torque function $K_{\mathrm{t}}(\theta)$ can be applied to reduce the torque ripple without knowing the stator's inductances.

\subsection{The reduction of torque ripple}

In the last part, for different stator currents, the torque function $K_{\mathrm{t}}(\theta)$ is nearly the same. Although, $K_{\mathrm{t}}(\theta)$ is not constant, but at each rotor position, it can be viewed as constant. So the constant torque can be applied to calculate the corresponding optimal currents by Eq. (12).

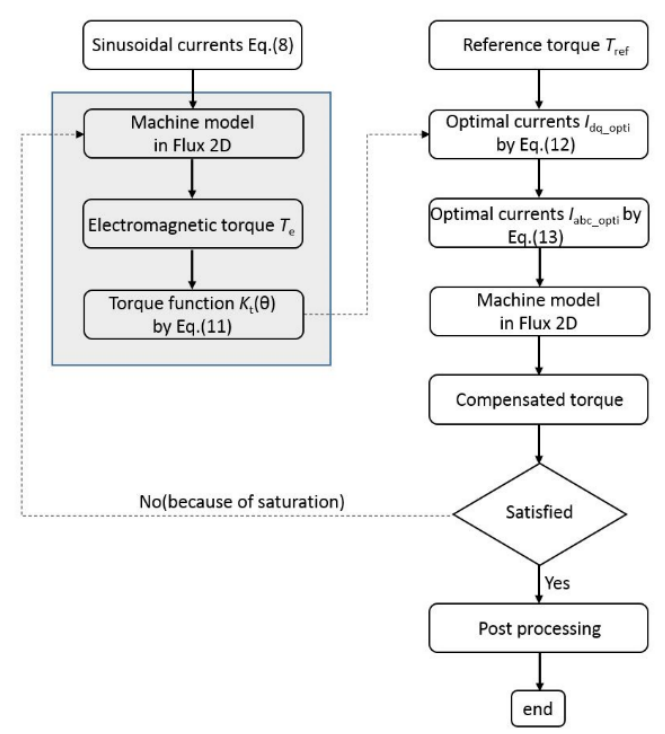

Fig. 5 The proposed method to reduce torque ripple

The method to minimize the torque ripple can be resumed by the following steps and is shown in Fig. 5 .

a) At first, the sinusoidal currents are supplied into the machine, and the torque with high harmonics $T_{\mathrm{e}}$ is obtained.

b) Besides, the torque function $K_{\mathrm{t}}(\theta)$ can be calculated by torque $T_{\mathrm{e}}$ and the current of d-axis $I_{\mathrm{d}}$. It should be emphasized that this parameter can be calculated just for one time and then can be used for different input currents if saturation is negligible and current angle is fixed.

c) Furthermore, the constant torque reference $T_{\text {ref }}$ which is the average torque produced by the sinusoidal currents and torque function $K_{\mathrm{t}}(\theta)$ are used to obtain the optimal current of d-axis and q-axis $\left(I_{\mathrm{dq} \text { opti }}\right)$ as shown by Eq. (12).

d) Then, the stator currents $\left(I_{\text {abc } \_o p t i}\right)$ can be calculated by the inverse of Park transformation as shown in Eq. (13).

e) Supplying the optimal stator currents into the SynRM, the compensated torque ( $\left(T_{e_{-} \text {optit }}\right)$ can be obtained; if the result is not satisfied because of saturation, the torque function should be recalculated.

f) At last, the results are analyzed in the post processing stage.

From Fig. 5 it can be concluded that the proposed method does not need the stator inductances because the torque function $K_{\mathrm{t}}(\theta)$ contains the stator inductances' information and it can be easily calculated by finite element analysis. According to Eq. (10), the optimal currents of dq-axis can be calculated 
$I_{d q_{-} \text {opti }}=\sqrt{\frac{\mathrm{T}_{r e f}}{K_{t}(\theta)}}$

The optimal currents of stator can be calculated by the optimal currents of dq-axis reference frame

$\boldsymbol{I}_{a b c_{-} o p t i}=\boldsymbol{C}_{32}^{T}(\theta) \boldsymbol{I}_{d q_{-} o p t i}$

\section{Simulation of torque ripple reduction}

\subsection{The optimal currents}

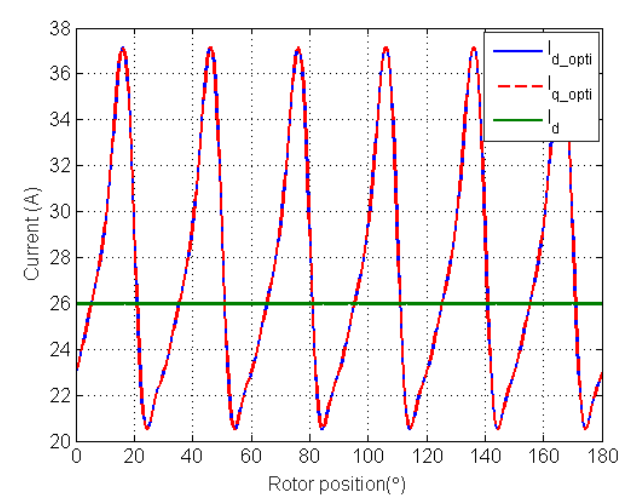

Fig. 6 The optimal currents of d-axis and q-axis

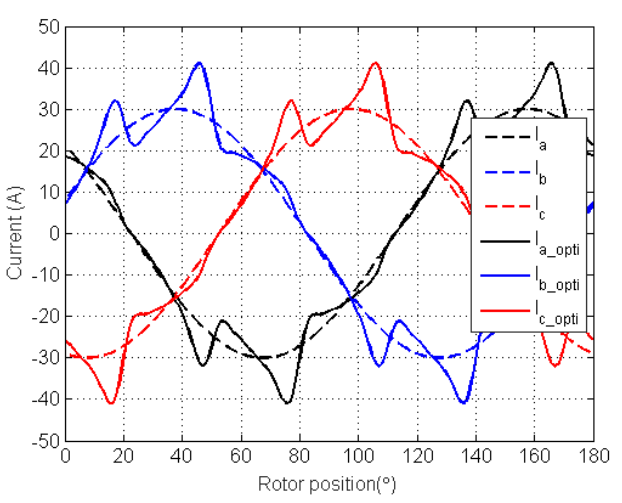

Fig. 7 The optimal currents of stator

To test the proposed method, simulation has been implemented in Flux2D. The supplied stator currents are sinusoidal $\left(I_{\mathrm{m}}=30 \mathrm{~A}\right)$. The constant torque reference is set as $0.2051 \mathrm{Nm}$ which is the mean value of the torque obtained by Flux 2D as shown in Fig. 3.

As shown in Fig. 6, the optimal $I_{\mathrm{d} \_ \text {opti }}$ is variable, while $I_{\mathrm{d}}$ calculated by sinusoidal currents is constant. Fig. 7 presents the optimal currents of three phases of stator which contain many harmonics. To minimize the torque ripple, the optimal currents should be supplied into the SynRM. Therefore, the currents are analyzed by fast Fourier transform (FFT) to obtain their analytical expressions. For example, $I_{\text {a } \_ \text {opti }}$ which contains up to the 25 th harmonic is given by Eq. (14). It can be seen that in addition to the fundamental current, the orders of currents' harmonics are $5,7,11,13,17,19,23$ and 25 .

$$
\begin{gathered}
I_{a_{-} \text {opti }}=31.58 \cos \left(\theta_{e}+0.7854\right)+3.861 \cos \left(5 \theta_{e}+2.5988\right)+3.861 \cos \left(7 \theta_{e}-2.1136\right)+ \\
1.712 \cos \left(11 \theta_{e}-1.3032\right)+1.712 \cos \left(13 \theta_{e}+0.2676\right)+0.6371 \cos \left(17 \theta_{e}+1.0531\right)+ \\
0.6371 \cos \left(19 \theta_{e}+2.6232\right)+0.1261 \cos \left(23 \theta_{e}+2.981\right)+0.1261 \cos \left(25 \theta_{e}-1.7317\right)
\end{gathered}
$$

Where $\theta_{e}$ is the rotor's electrical position.

To simplify the expressions, the optimal stator currents are defined

$$
\boldsymbol{I}_{\text {abc_opti }}=\left[\begin{array}{c}
\sum_{i=1,6 n \pm 1} H_{i} \cos \left(i\left(\theta+\varphi_{i}\right)\right) \\
\sum_{i=1,6 n \pm 1} H_{i} \cos \left(i\left(\theta-\frac{2 \pi}{3}+\varphi_{i}\right)\right) \\
\sum_{i=1,6 n \pm 1} H_{i} \cos \left(i\left(\theta+\frac{2 \pi}{3}+\varphi_{i}\right)\right)
\end{array}\right]
$$

Where $H$ is the amplitudes of the harmonics of the stator currents; $i$ is the order of the harmonics and it can be expressed as $6 n \pm 1$ when $i>1$ and $n$ is positive integer; $\varphi_{i}$ is the phase of the currents' harmonics.

As stated in [26], the 5th and 7th harmonics of stator currents become the 6th harmonic in the d-q reference frame. It is assumed that there exists the similar relation between the harmonics of stator currents and the harmonics of torque. For example, the 5 th and 7 th harmonics of stator currents compensate the 6 th harmonic of torque. $m$ is defined as the order of torque harmonics. Therefore, to minimize the $m$ th harmonic, the optimal stator currents should contain at least the $(m-1)$ th and the $(m+1)$ th harmonics. 


\subsection{The compensated torque}

After having obtained the optimal currents, torque ripple reduction can be analyzed. The optimal currents containing different orders of harmonics are supplied as expressed in Eq. (15). In this part, to reduce $m$ th torque harmonic, the optimal current harmonics whose order are not larger than $(m+1)$ th are all supplied. For instance, the optimal currents when $i=13$ contain the fundamental, 5 th, 7 th, 11 th, 13 th harmonics. The analysis of this section does not consider the effect of saturation which will be studied in the fourth part.

The results of the compensated torque are presented in Fig. 8. And with different values of $i$ which means different compensations of torque ripple, the average torque and torque ripple are presented in Fig. 9 and in Fig. 10. Besides, when $i=0$, the results in Fig. 10 are produced by sinsusoidal currents which means that the torque is uncompensated.

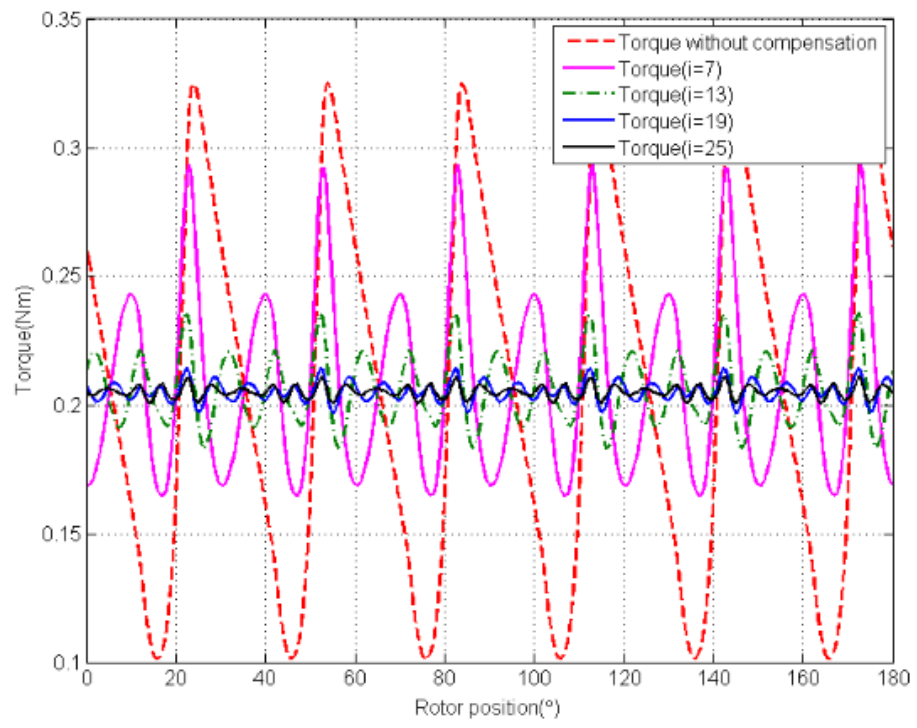

Fig. 8 The results of optimized torque

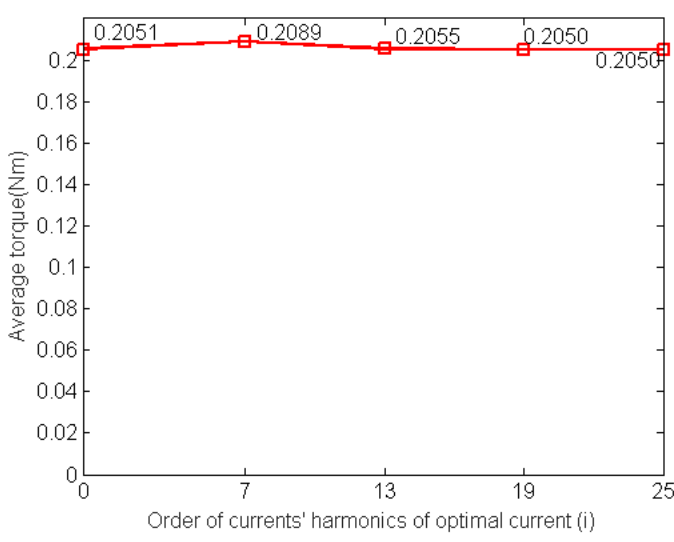

Fig. 9 The average torque with different currents' harmonics

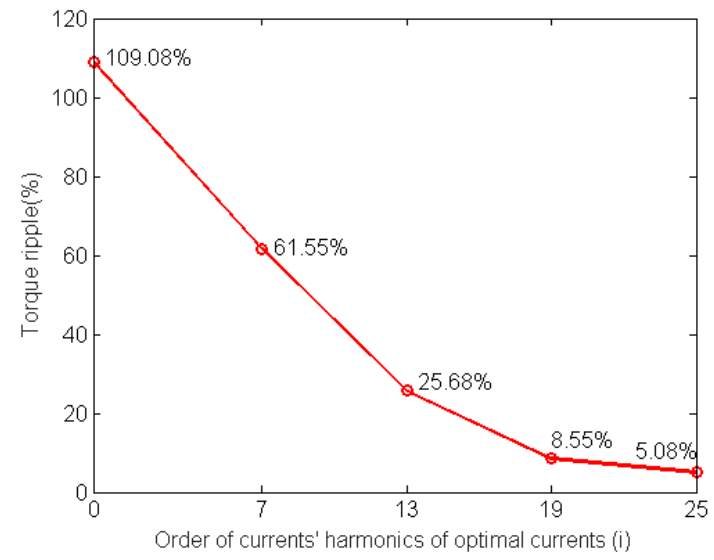

Fig. 10 The remained torque ripple with different currents' harmonic

Torque ripple is calculated by

$$
\Delta T=\frac{T_{\max }-T_{\min }}{T_{\text {mean }}} \times 100 \%
$$

Where $T_{\max }, T_{\min }$ and $T_{\text {mean }}$ are the maximal value, minimal value and mean value of torque respectively. Fig. 8 presents that compared with uncompensated torque, the torque ripple is reduced greatly with the optimal currents. The average torque in Fig. 9 is nearly constant $0.2051 \mathrm{Nm}$ which equals the constant torque reference. Moreover, 
it can be noticed that with more currents' harmonics, the torque ripple is reduced greater from $109.08 \%$ to $5.08 \%$ as presented in Fig. 10. When the order of current harmonic is 19, the rest of torque ripple becomes below $10 \%$.

According to the results presented by Fig. 9 and Fig. 10, the torque ripple is minimized and the average torque is not changed. It implies that the currents' harmonics are mainly applied to reduce the torque ripple and have little influence on the average torque.

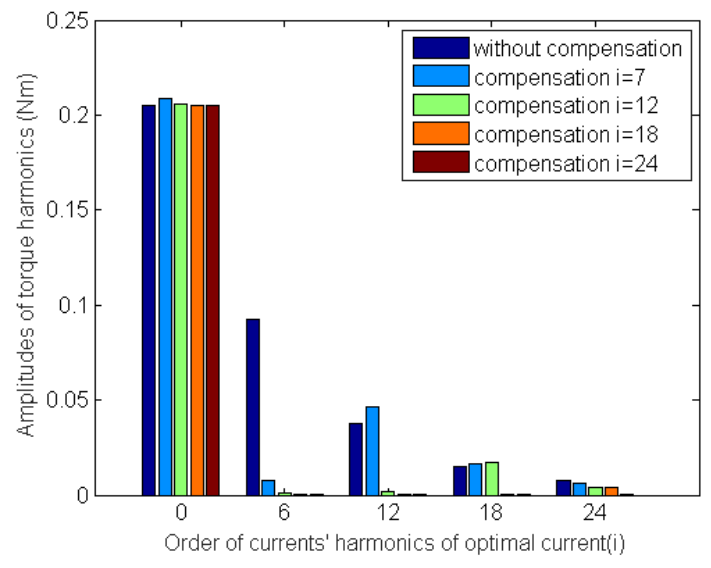

Fig. 11 Each harmonic of the torque with different

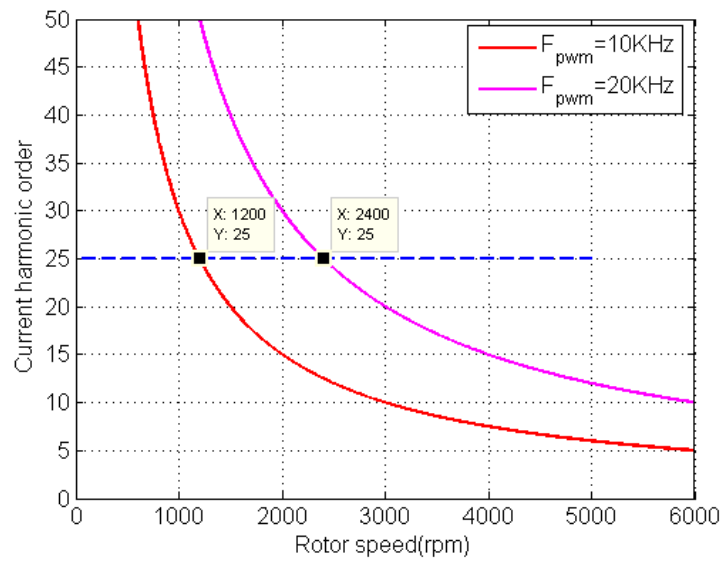

Fig. 12 Limit of PWM's frequency

currents' harmonics

\subsection{Analysis of the results}

The compensated torques obtained by supplying different currents' harmonics are now analyzed. The values of torque harmonics are more important, so only their amplitudes are shown in Fig. 11. It presents each torque harmonic value of torque at different compensation situations. The average torques are shown when $m$ is 0 .

Firstly, it can be concluded that the 6th, 12th, 18th and 24th harmonics of torque are decreased greatly respectively with supplying the corresponding optimal currents $(i=7,13,19,25)$. For example, compared with the torque without compensation, the 6th torque harmonic of the compensated torque produced by the optimal current when its order $\mathrm{i}=7$, is reduced greatly. It implies that the relation between the harmonics of stator currents and the harmonics of torque really exists. $(m-1)$ th and the $(m+1)$ th currents' harmonics can reduce the $m$ th $(\mathrm{m}=6,12, \ldots)$ torque harmonic. Therefore, before selecting the optimal currents, it's better to analyze the original torque to find out the orders of torque harmonics which cause severe ripple and should be compensated. And then the optimal currents with appropriate order of harmonic can be defined ahead. For instance, if the 6th, 12th and18th torque ripple should be reduced (torque ripple is below 10\%) for the studied machine, it's better to supply the stator currents with the 5 th, 7 th, 11th, 13th, 17 th and 19th harmonics $(i=19)$.

Furthermore, compared with the 6 th harmonic of torque when $i=7$, the 6 th torque harmonic when $i=13,19$ and 25 is much reduced. The similar conclusion can also be drawn for the 12 th torque harmonic $(i=13,19$ and 25$)$ and 18th torque harmonic ( $i=19$ and 25). It means that there exist couplings among the harmonics of currents. Decreasing $m$ th torque harmonic could also reduce the lower order $(<m)$ torque harmonic further.

In addtition, according to the average torque and torque ripple reduction of the studied machine, the optimal order of the current harmonics is 19. But the frequencies of currents' harmonics are proportional to the rotor's speed. Higher speed will lead to higher frequencies of current harmonics. However, the current's frequencies will be restricted by the frequency of closed loop control and the PWM's frequency. As a result, the seletion of the optimal order will be influenced by control loop's bandwidth and PWM's frequency.

For example, if the frequency of $\operatorname{PWM}\left(F_{\mathrm{PWM}}\right)$ is set as $10 \mathrm{kHz}$, to get better operation of the machine and for 
safety, the maximal frequency $\left(F_{\text {imax }}=1000 \mathrm{~Hz}\right)$ of current hamonic is defined as one tenth of $F_{\text {PWM }}$. So the reduction of torque ripple can be limited by the PWM's frequency because this frequency will limit the frequencies of current harmonics. As presented in Fig. 12, if the rotor speed is below 1200rpm, the 25th current harmonic can be applied to reduce the 24th torque harmonic. When the speed is increased, the maximal order of current harmonics should be decreased which means 24th torque ripple cannot be compensated.

Besides, if high order torque harmonic which causes serious torque ripple exists and the machine is also desired to operate at high speed, $F_{\mathrm{PWM}}$ should be increased. For example, in Fig. 12, if $F_{\mathrm{PWM}}$ is improved from $10 \mathrm{kHz}$ to $20 \mathrm{kHz}$, the 25th current harmonic can be applied and the machine could also operate at higher speed (2400rpm). Nevertheless, high frequency PWM may result in undesired noise and increase losses. In conclusion, this limit depends on the order of torque ripple which should be minimized. For different machines, the orders could be different. Usually, the lower orders (6th and 12th) of torque harmonic are more important.

\section{Effect of saturation on the proposed method}

Magnetic saturation is not considered in the previous study. However, according to Fig. 7, it can be seen that the amplitude of the optimal current is higher than that of sinusoidal current which means the optimal current can result in saturation easier than the sinusoidal current. Hence, it is necessary to study when and how the proposed method could cause saturation and the effect of saturation on reduction of torque ripple in the synchronous reluctance machine.

The average values of the inductances of dq-axis are calculated by finite element method to represent the variation of saturation [22]. As shown in Fig. 13, $L_{\mathrm{d}}$ and $L_{\mathrm{q}}$ are decreased as the stator current becomes larger. It can be seen that saturation can be negligible when $I_{\mathrm{m}}$ is smaller than $50 \mathrm{~A}$ for the studied machine, small if $I_{\mathrm{m}}$ is between $50 \mathrm{~A}$ and $60 \mathrm{~A}$ and noticeable when $I_{\mathrm{m}}$ is larger than $60 \mathrm{~A}$.

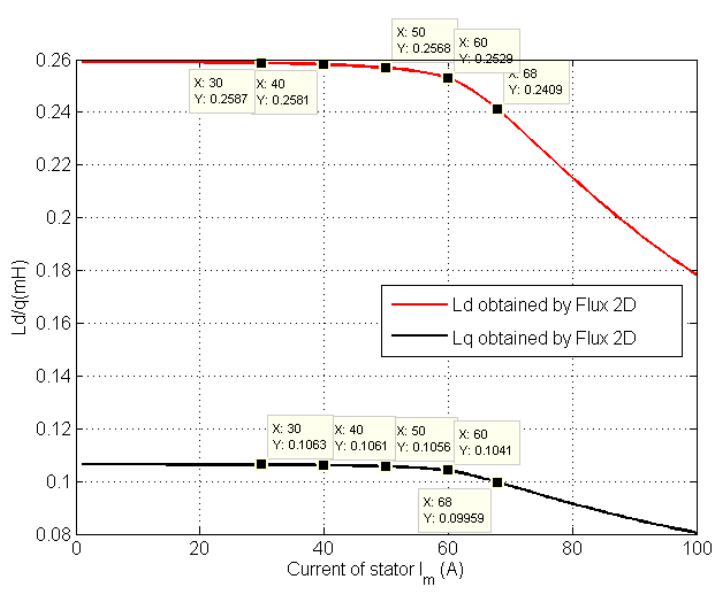

Fig. 13 Variations of $L_{\mathrm{d}}$ and $L_{\mathrm{q}}$ for different $I_{\mathrm{m}}$

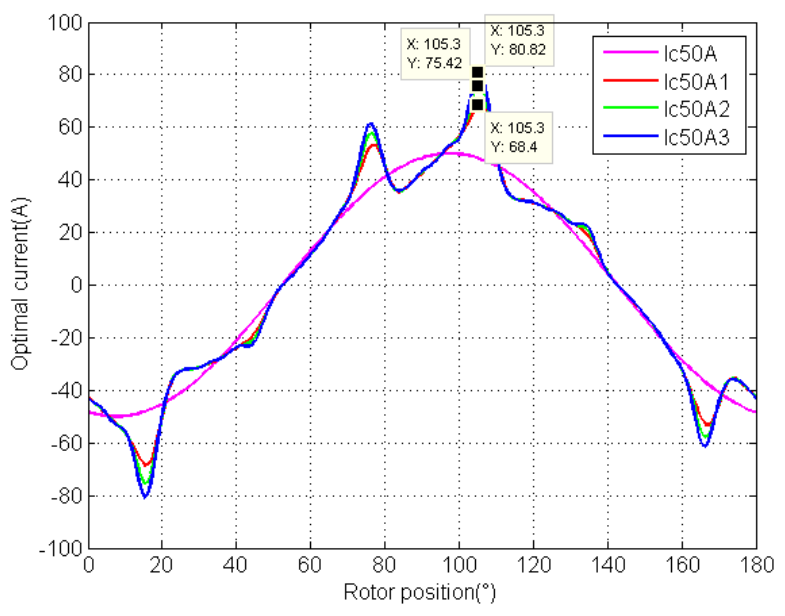

Fig. 14. The optimal stator current $\left(I_{\mathrm{m}}=50 \mathrm{~A}, i=25\right)$

Therefore, the proposed method is applied when $I_{\mathrm{m}}$ equals $50 \mathrm{~A}$ (sinusoidal currents) to study the influence of saturation. To compare the results of torque ripple reduction with and without magnetic saturation, the maximum current harmonic order is fixed to 25 . Torque ripple is then decreased to $5.08 \%$ without saturation as illustrated in Fig. 10. Although, the saturation could increase the orders of optimal current harmonics from 25th to 37th, the emerging harmonics (29th and 31th, 35th and 37th) have very small amplitudes and their influence on the torque ripple reduction could be neglected. So the maximal order of optimal current harmonic is considered as 25 .

The maximal value of the optimal current ( $I_{\mathrm{c} 50 \mathrm{~A} 1}$ as shown in Fig. 14) of the sinusoidal current $I_{\mathrm{c} 50 \mathrm{~A}}$ is $68.4 \mathrm{~A}$ which can result in serious saturation according to Fig. 13. As a result, the compensated torque $T_{\mathrm{e} 50 \mathrm{~A} 1}$ as shown in 
Fig. 15 has still high harmonics. The rest of torque ripple (23.84\%) is much larger than that obtained when the saturation is negligible in Fig. 8 which is $5.08 \%$. Hence, the saturation resulting from the optimal currents could deteriorate the compensation of torque ripple and reduce the effectiveness of the proposed method.

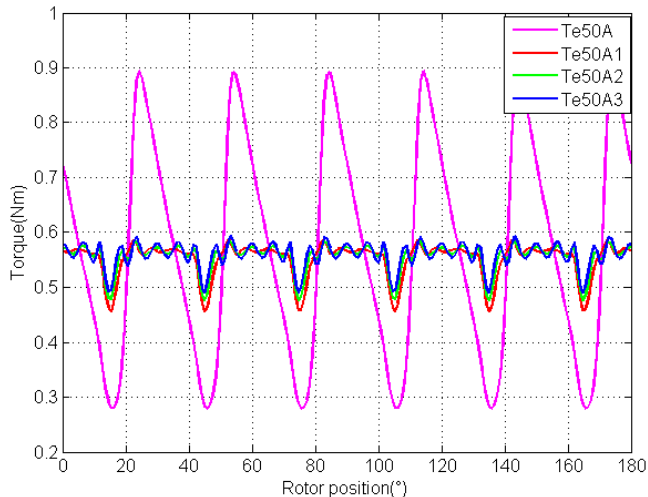

Fig. 15 Comparison of torques $\left(I_{\mathrm{m}}=50 \mathrm{~A}, i=25\right)$

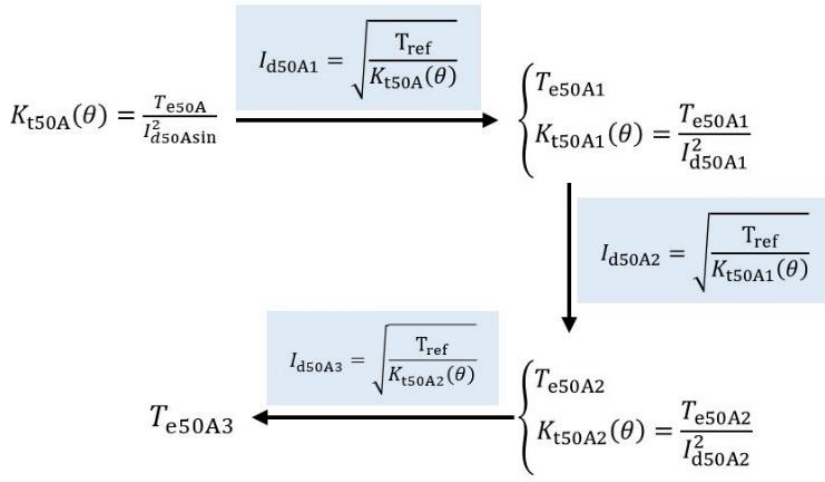

Fig. 16 Calculation of torque functions and the optimal currents

Then the effect of saturation on torque ripple reduction is analyzed. When saturation is not negligible, the inductances of SynRM will be decreased. Since the torque function $K_{\mathrm{t}}(\theta)$ contains the information of stator inductances, it can be affected by saturation. $K_{\mathrm{t}}(\theta)$ should be recalculated for the purpose of obtaining new optimal currents to reduce torque ripple and to clarify how the saturation affects the proposed method.

According to the procedures presented in Fig. 5, two more torque functions, $K_{\mathrm{t50A} 1}$ and $K_{\mathrm{t} 50 \mathrm{~A} 2}$, are calculated and presented in Fig. 17. The process is introduced in Fig. 16. $T_{\mathrm{e} 50 \mathrm{~A}}$ is the uncompensated torque produced by sinusoidal current $\left(I_{\mathrm{m}}=50 \mathrm{~A}, I_{\mathrm{d} 50 \mathrm{~A} s i n}\right.$ is the current in d-axis). $K_{\mathrm{t} 50 \mathrm{~A}}$ is the torque function calculated by $T_{\mathrm{e} 50 \mathrm{~A}}$ and $I_{\mathrm{d} 50 \mathrm{Asin}}$. The torque function $K_{\mathrm{t} 50 \mathrm{~A}}$ is identical to $K_{\mathrm{t} 30 \mathrm{~A}}$ in Fig. 17 which means the saturation when $I_{\mathrm{m}}=50 \mathrm{~A}$ is negligible. The constant torque reference $T_{\text {ref }}$ is the average value of $T_{\mathrm{e} 50 \mathrm{~A}} . K_{\mathrm{t} 50 \mathrm{~A} 1}$ and $K_{\mathrm{t} 50 \mathrm{~A} 2}$ are applied to obtain the optimal currents $I_{\mathrm{d} 50 \mathrm{~A} 2}$ and $I_{\mathrm{d} 50 \mathrm{~A} 3}$. The corresponding optimal stator currents $I_{\mathrm{c} 50 \mathrm{~A} 2}$ and $I_{\mathrm{c} 50 \mathrm{~A} 3}$ are presented in Fig. 14. It's obvious that the saturation is worse from $I_{\mathrm{c} 50 \mathrm{~A}}$ to $I_{\mathrm{c} 50 \mathrm{~A} 3}$.

The compensated torques produced by $I_{\mathrm{c} 50 \mathrm{~A} 1}, I_{\mathrm{c} 50 \mathrm{~A} 2}$ and $I_{\mathrm{c} 50 \mathrm{~A} 3}$ are introduced in Fig. 15. The compensated torques have low ripple harmonics at some positions, for example from $20^{\circ}$ to $40^{\circ}$. But the torque harmonics in Fig. 15 are still a little high. The minimal values of the compensated torques appear regularly. It's supposed that saturation results in this phenomena. The torque can be viewed as the product of torque function and current of $d-$ axis. Therefore, the corresponding optimal currents $I_{\mathrm{d} 50 \mathrm{~A} 1}, I_{\mathrm{d} 50 \mathrm{~A} 2}$ and $I_{\mathrm{d} 50 \mathrm{~A} 3}$ of the optimal stator currents $I_{\mathrm{c} 50 \mathrm{~A} 1}$, $I_{\mathrm{c} 50 \mathrm{~A} 2}$ and $I_{\mathrm{c} 50 \mathrm{~A} 3}$ are presented in Fig. 18 in order to explain the residual 6 th torque harmonic. It's obvious that these optimal currents are periodical and contains harmonics. Consequently, the saturation is changed periodically. For instance, when $I_{\mathrm{d} 50 \mathrm{~A} 1}$ becomes bigger than $50 \mathrm{~A}$, saturation becomes serious. As a result, $K_{\mathrm{t} 50 \mathrm{~A} 1}$ becomes smaller than $K_{\mathrm{t} 50 \mathrm{~A}}$. When $I_{\mathrm{d} 50 \mathrm{~A} 1}$ becomes smaller than $50 \mathrm{~A}$, saturation becomes negligible. Therefore, $K_{\mathrm{t} 50 \mathrm{~A} 1}$ becomes identical to $K_{\mathrm{t} 50 \mathrm{~A}}$.

Taking the most serious position for example, when $I_{\mathrm{d} 50 \mathrm{Al}}=61.51 \mathrm{~A}$ at $\theta=15.3^{\circ}$, the saturation at the current $I_{\mathrm{d} 50 \mathrm{~A} 1}$ becomes worse compared with the saturation when $I_{\mathrm{d} 50 \mathrm{~A}}=43.3 \mathrm{~A}$ at $\theta=15.3^{\circ}$. The difference between $K_{\mathrm{t} 50 \mathrm{~A} 1}$ and $K_{\mathrm{t} 50 \mathrm{~A}}$ is large. But the optimal current $I_{\mathrm{d} 50 \mathrm{~A} 1}$ is calculated by $K_{\mathrm{t} 50 \mathrm{~A}}$. Consequently, the electrical torque $(0.4565 \mathrm{Nm}$ in Fig. 15$)$ produced by $I_{\mathrm{d} 50 \mathrm{~A} 1}$ and the actual $K_{\mathrm{t} 50 \mathrm{~A} 1}$ is much smaller than the constant torque reference $(0.5669 \mathrm{Nm})$. The similar conclusion can be obtained for the other compensated torques produced by the optimal currents such as $I_{\mathrm{d} 50 \mathrm{~A} 2}$ and $I_{\mathrm{d} 50 \mathrm{~A} 3}$. Hence, when the optimal current is not large enough to cause serious saturation, the torque ripple can be reduced greatly; if the optimal current exceeds a threshold value which causes noticeable saturation, the torque ripple cannot be reduced completely. The residual torque harmonics depend on the difference between the torque function which is applied to calculate the optimal currents and the actual one produced by 
saturation.

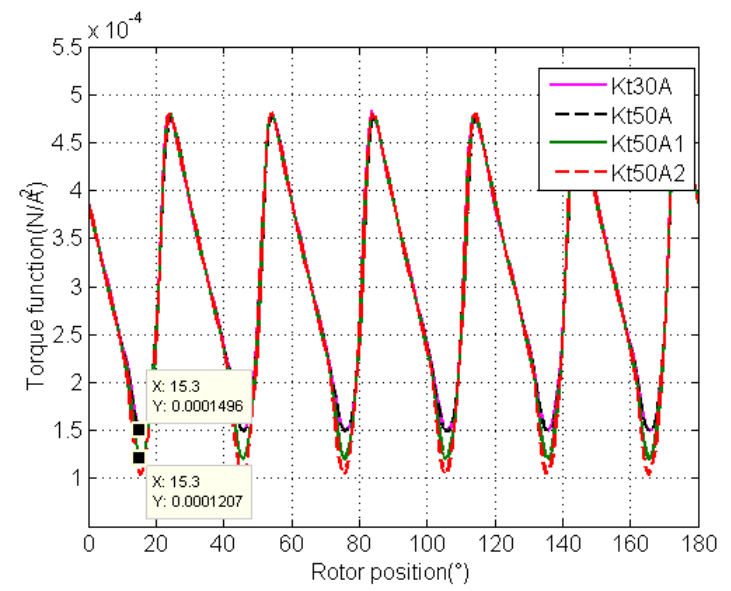

Fig. 17 The torque function $K_{t}(\theta)$ at different saturation

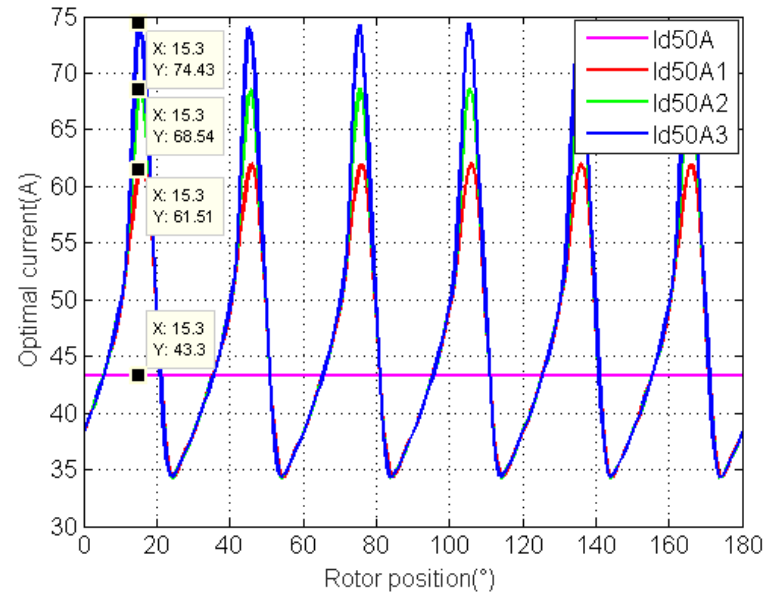

Fig. 18 Optimal currents $I_{\mathrm{d}}$

What's more, the influence of saturation on the compensation of different torque harmonics is also presented in Fig. 19. Compared with the reduction of torque ripple when saturation is serious, the compensation without saturation $\left(\Delta T_{30 \mathrm{~A}}\right)$ presents less residual torque ripple at each compensation especially for the high torque harmonics. For example, when $i=25$, the torque harmonics whose order is below 24th are compensated. If saturation is negligible, the residual torque ripple is $5.08 \%$ while the residual torque ripple with saturation $\left(\Delta T_{50 \mathrm{~A}}\right.$, $\Delta T_{50 \mathrm{~A} 2}$ and $\left.\Delta T_{50 \mathrm{~A} 3}\right)$ is about $20 \%$. Besides, compared the three compensations with saturation, the $\Delta T_{50 \mathrm{~A} 1}$ presents higher residual torque ripple than $\Delta T_{50 \mathrm{~A} 2}$ and $\Delta T_{50 \mathrm{~A} 3}$. Because the increased saturation from $I_{\mathrm{d} 50 \mathrm{~A}}$ to $I_{\mathrm{d} 50 \mathrm{~A} 1}$ is worse than that caused by changing the optimal current from $I_{\mathrm{d} 50 \mathrm{~A} 1}$ to $I_{\mathrm{d} 50 \mathrm{~A} 2}$ or from $I_{\mathrm{d} 50 \mathrm{~A} 2}$ to $I_{\mathrm{d} 50 \mathrm{~A} 3}$. The saturation deteriorates the torque ripple reduction.

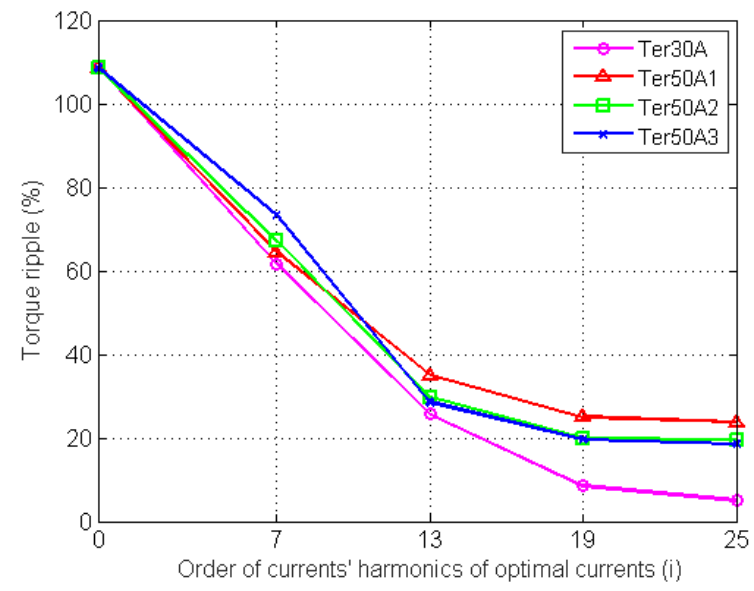

Fig. 19 Residual torque ripple

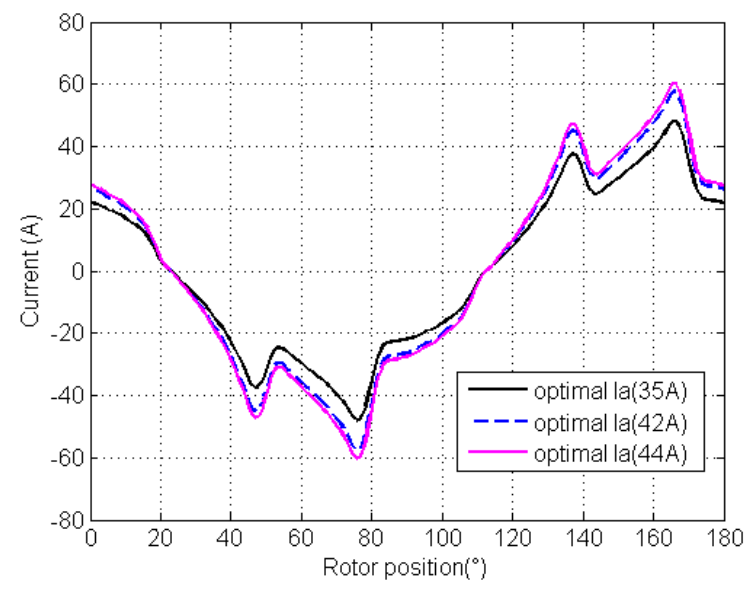

Fig. 20 The optimal currents for different sinusoidal currents

Table 1 Results of three different currents

\begin{tabular}{c|c|c|c}
\hline $\boldsymbol{I}_{\mathbf{m}}$ & $35 \mathrm{~A}$ & $42 \mathrm{~A}$ & $44 \mathrm{~A}$ \\
\hline $\boldsymbol{I}_{\text {optimax }}$ & $47.99 \mathrm{~A}$ & $57.56 \mathrm{~A}$ & $60.28 \mathrm{~A}$ \\
\hline $\boldsymbol{T}_{\mathrm{e}}$ & $7.49 \%$ & $8.73 \%$ & $9.73 \%$ \\
\hline
\end{tabular}

According to Fig. 13 the maximal value of the optimal current is limited to $60 \mathrm{~A}$ which means the saturation is not serious. Based on the proposed method, after several simulations, the maximal value of sinusoidal currents which can avoid saturation is found. Fig. 20 shows the optimal currents for different sinusoidal currents and the results are presented in Table 1. It can be seen that when $I_{\mathrm{m}}=44 \mathrm{~A}$, the maximal value of its corresponding optimal 
currents is about $60 \mathrm{~A}$ and the rest torque ripple is $9.73 \%$ which is satisfying. So the proposed method can provide the best compensation for the studied machine when $I_{\mathrm{m}}$ is not larger than $44 \mathrm{~A}$. However, when $I_{\mathrm{m}}$ is larger than $44 \mathrm{~A}$, torque ripple can also be reduced, but the rest of torque ripple depends on the saturation which is related to the amplitude of the optimal currents.

\section{Copper losses analysis}

As presented in the previous section, compared with the sinusoidal current, the corresponding optimal currents are larger and have many harmonics which could increase the losses. It is interesting to evaluate the increased losses and know how the compensation of torque ripple affects the losses. The copper losses are about $96 \%$ of the losses of the studied machine and the iron losses are very small. So the iron losses are neglected in this part.

The copper losses consumed by the resistance of a three phases SynRM can be represented

$P_{c}=3 I_{\text {rmsopti }}^{2} R$

The root mean square value $I_{\text {rmsopti }}$ of the optimal currents which contain many harmonics can be expressed

$$
I_{\text {rmsopti }}=\sqrt{\sum_{i=1,5,7 \ldots \frac{I_{i}^{2}}{2}}}
$$

Where $I_{\mathrm{i}}$ is the maximal value of each current harmonic.

Based on (17), the increased copper losses resulted by reducing torque ripple can be expressed

$$
\Delta P_{c}=3\left(\sum_{i=1,5,7 \ldots} \frac{I_{i}^{2}}{2}-I_{r m s s i n}^{2}\right) R
$$

Where $I_{\mathrm{rmssin}}$ is the root mean square value of corresponding sinusoidal current.

Besides, different compensations of torque ripple require different harmonics of the optimal currents which can cause different increased copper losses. Therefore, the torque ripple compensation can affect the losses and it should consider the torque ripple reduction and copper losses together to choose the optimal order of current's harmonics.

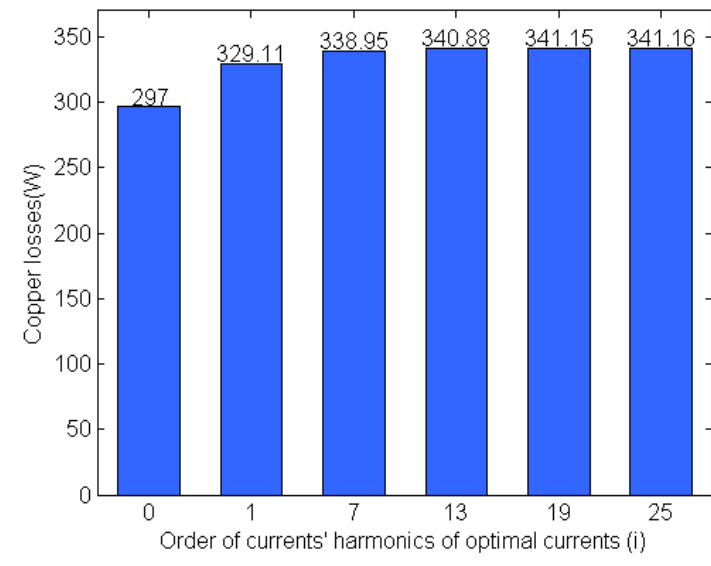

(a) the copper losses

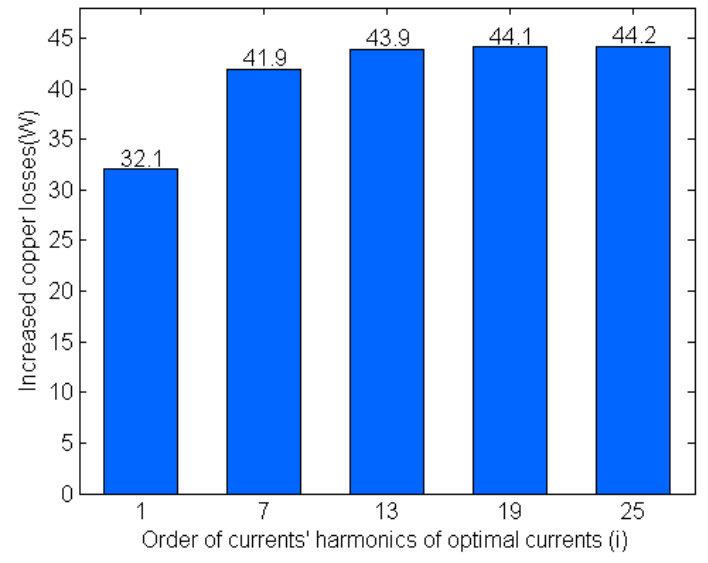

(b) the increased copper losses $\left(\Delta P_{\mathrm{c}}\right)$

Fig. 21 The copper losses with different current's harmonics $(i)$

The copper losses of the studied machine by supplying different current's harmonics are calculated by (17) and presented in Fig. 21 (a). When $i=0$, it means the losses caused by sinusoidal current whose amplitude is $30 \mathrm{~A}$ and there is no compensation of torque ripple. When $i=1$, it means the losses caused by first harmonic of the optimal currents which is $31.58 \mathrm{~A}$ and is sinusoidal as presented in (14). For the other values of $i$, the definition can be found in (15). 
It can be concluded that compared with the copper losses produced by sinusoidal currents, the copper losses caused by the optimal currents are much larger. Because it needs current harmonics to reduce torque ripple which results in the increased copper losses. Besides, with more currents' harmonics, the copper losses are increased larger. For instance, the copper losses are increased from $297 \mathrm{~W}$ to $341.16 \mathrm{~W}$ when the sinusoidal currents is replaced by the optimal currents which contain 25 th harmonic.

What's more, when $i=1$, the increased copper losses is the largest. Because the first current harmonic (31.58A) of the optimal current (as presented by (14)) is a little larger than the original sinusoidal current (30A). Therefore, the copper losses produced by this current harmonic is increased greatly. But the torque ripple produced just by the first current harmonic of the optimal current will not be reduced. The optimal current contains all the harmonics besides the first current component. The other current harmonics (5th, 7th, 11th, 13th...) cannot reduce torque ripple without the first component (31.58A) and vice versa. So the increased copper losses resulted by the first component of the optimal current are also considered to reduce torque ripple. On the other hand, for SynRMs with other rotor topologies such as massive rotor and flux barriers rotor, the amplitudes of the first current harmonics are increased very small and the copper losses produced by this current harmonic are also very small [27].

Considering the torque ripple reduction, the increased copper losses can be analyzed. Torque ripple in Fig. 10 is reduced from $109.08 \%$ to $5.08 \%$, while the increased copper losses by reducing one more torque harmonic are much less increased. For example, the increased copper losses by decreasing the torque ripple from $61.55 \%$ to $25.68 \%$ are $2.0 \mathrm{~W}$ (from $41.9 \mathrm{~W}$ to $43.9 \mathrm{~W}$ in Fig. 21 (b)); when the increased copper losses by decreasing the torque ripple from $25.68 \%$ to $8.55 \%$ are even smaller $0.2 \mathrm{~W}$. It means that adding higher order current harmonics ( $\mathrm{i}>7)$, the copper losses are increased slower. And the copper losses increased by adding two more current harmonics can be negligible when torque ripple is decreased to a threshold value which is $25.68 \%$ for the studied machine.

The different increased copper losses produced by decreasing different order torque ripple can be explained from the view of the torque ripple reduction. It can be seen that for the harmonics of the torque without compensation in Fig. 11, the 6th harmonic of torque ripple is larger than other torque harmonics and to reduce this harmonic, it needs larger current harmonics. As a result, the increased copper losses (without considering the losses caused by the fundamental current harmonic) are mainly used to decrease the 6th torque ripple. The copper losses consumed to reduce the torque harmonics whose order are higher than 6 are very small and can be neglected. Therefore, the selection of the order of current's harmonics depends mainly on the requirement of torque ripple reduction.

\section{Conclusion}

In this paper, a method to decrease torque ripple of synchronous reluctance machine is proposed. The torque function is defined to calculate the optimal non-sinusoidal currents in order to minimize torque ripple. It does not need to obtain the stator inductances which can save effort. Results of simulation in Flux 2D verified the method. The torque ripple can be reduced from $109.08 \%$ to $5.08 \%$. Besides, it can be found that each pair of current harmonics $(6 \mathrm{n} \pm 1)$ can be applied to reduce the corresponding torque ripple (6n). To minimize torque ripple below $10 \%$, the optimal current should contain at least the 19th harmonic for the studied machine.

The torque ripple reduction can be efficiently satisfied under the instantaneous current limit of $60 \mathrm{~A}$ for our machine. However, the saturation can affect the proposed method for higher current. Torque ripple compensation needs then to compute again the torque function in saturation conditions according an iterative process.

Thirdly, the increased copper losses produced by adding different current harmonics are also analyzed. This method increased the fundamental harmonic of the optimal current which could produce most copper losses. It 
also showed that to decrease the larger torque ripple whose order is low, causes more losses. To reduce the high frequency torque ripple requires little losses.

In the future, several points can be studied. The research will focus on experiment to verify the method further. Besides, the iron losses, inverter losses produced by the current harmonics should also be analyzed. At last, the torque ripple reduction could influence vibration and acoustic noise of synchronous reluctance machines. It will be studied later.

\section{References}

[1] W. Chai, W. Zhao, B. I. Kwon, Optimal Design of Wound Field Synchronous Reluctance Machines to Improve Torque by Increasing the Saliency Ratio. DOI 10.1109/TMAG.2017.2707459, IEEE Transactions on Magnetics.

[2] H. Wu, D. Depernet, V. Lanfranchi, A Survey of Synchronous Reluctance Machine used in Electric Vehicle, in: Int. Conf. on Renewable Energy: Generation and Applications ICREGA, Belfort, France, Feb. 8-10, 2016.

[3] A. Fratta, G.P. Troglia, A.Vagati, et al. Evaluation of torque ripple in high performance synchronous reluctance machines, in: IEEE Industry Applications Society Annual Meeting, New York, Oct.2-8, 1993, pp.163-170.

[4] N. Bianchi, S. Bolognani, D. Bon, Rotor flux-barrier design for torque ripple reduction in synchronous reluctance motors, in: IEEE Industry Applications Conference Forty-First IAS Annual Meeting, Florida, Oct.812,2006, pp.1193-1200.

[5] N. Bianchi, S. Bolognani, D. Bon, Rotor flux-barrier design for torque ripple reduction in synchronous reluctance and PM-assisted synchronous reluctance motors, IEEE Transactions on Industry Applications 45 (2009) 921-928.

[6] M. Sanada, K. Hiramoto, S. Morimoto, Torque ripple improvement for synchronous reluctance motor using asymmetric flux barrier arrangement, in: IEEE Industry Applications Conference IAS Annual Meeting, Salt Lake City,Oct.12-16, 2003, pp.250-255.

[7] X.B. Bomela, M.J. Kamper, Effect of machine design on performance of reluctance synchronous machine, in: Industry Applications Conference and World Conference on Industrial Applications of Electrical Energy, Rome, Oct.8-12, 2000, pp.515-522.

[8] E. Rakgati, M. Karnper. Torque performance of optimally designed three and five phase reluctance synchronous machines with two rotor structures, in: AFRICON 2004, Gaborone, Botswana, Sep.15-17, 2004, pp. 625-629.

[9] T. Hamiti, T. Lubin, L. Baghli, et al. Modeling of a synchronous reluctance machine accounting for space harmonics in view of torque ripple minimization, Mathematics and Computers in Simulation 81 (2010) 354366.

[10] P.H. Truong, D. Flieller, N.K. Nguyen, et al. Torque ripple minimization in non-sinusoidal synchronous reluctance motors based on artificial neural networks, Electric Power Systems Research 140 (2016) 37-45.

[11] D. Flieller, N.K. Nguyen, P. Wira, G. Sturtzer, A self-learning solution for torque ripple reduction for nonsinusoidal permanent-magnet motor drives based on artificial neural networks, IEEE Transactions on Industrial Electronics 61 (2014) 655-666.

[12] N. Nakao, K. Akatsu, Torque ripple control for synchronous motors using instantaneous torque estimation, in: IEEE Energy Conversion Congress and Exposition, Phoenix, Sep.17-22,2011, pp.2452-2459.

[13] X.Tu, L. A.Dessaint, El Kahel, M., A.Barry, Modeling and experimental validation of internal faults in salient pole synchronous machines including space harmonics, Mathematics and Computers in Simulation 71 (2006) 
425-439.

[14] H. Wu, D. Depernet, V. Lanfranchi. Analysis and minimization of torque ripple in synchronous reluctance machine by supplying non-sinusoidal currents. In: ELECTRIMACS, Toulouse, France, July 4-6, 2017.

[15] MAH. Rasid, V. Lanfranchi, KEK. Benkara, et al. Simple lumped parameter thermal model with practical experimental fitting method for synchronous reluctance machine, in: IEEE Power Electronics and Applications (EPE), Lille, France, Sep.2-6, 2013, pp.1-10.

[16] C. Doc, Contribution à la conception et au dimensionnement d'un actionneur d'embrayage, Université de Technologie de Compiègne 2010.

[17] H. Jia, M. Cheng, W. Hua, et al. Torque ripple suppression in flux-switching PM motor by harmonic current injection based on voltage space-vector modulation, IEEE Transactions on Magnetics 46 (2010) 1527-1530.

[18] S. Yammine, Contribution to the Synchronous Reluctance Machine Performance Improvement by Design Optimization and Current Harmonics Injection, University of Toulouse 2015.

[19] G.H. Lee, S. I. Kim, J. P. Hong, et al. Torque ripple reduction of interior permanent magnet synchronous motor using harmonic injected current, IEEE Transactions on Magnetics 44 (2008) 1582-1585.

[20] J. P. Louis, Control of non-conventional synchronous motors. John Wiley \& Sons. 2013.

[21] G. Rigatos, P. Siano, M. Jovanovic, S. Ademi, P. Wira, Z. Tir, Nonlinear optimal control for Synchronous Reluctance Machines, in: IEEE Compatibility, Power Electronics and Power Engineering (CPE-POWERENG), Cadiz, Spain, Apr.4-6,2017,pp.594-599.

[22] H. Wu, D. Depernet, V. Lanfranchi. Etude de l'influence de la saturation sur la réduction des ondulations de couple d'une machine synchrone à réluctance variable, in: Conférence des Jeunes Chercheurs en Génie Electrique, Arras, France, May 30-june 1, 2017.

[23] C. DOC, LANFRANCHI, Vincent, FRIEDRICH, Guy. Inverter topology comparison for remedial solution in transistor faulty case, in: European Conference on Power Electronics and Applications, Aalborg, Denmark, Sep. 2-5, 2007 pp.1-8.

[24] P. Niazi, H.A. Toliyat, A. Goodarzi. Robust maximum torque per ampere (MTPA) control of PM-assisted SynRM for traction applications, IEEE Transactions on Vehicular Technology 56 (2007) 1538-1545.

[25] R. R. Moghaddam, F. Magnussen, C. Sadarangani, Theoretical and experimental reevaluation of synchronous reluctance machine, IEEE Transactions on Industrial Electronics 57 (2010) 6-13.

[26] P. Pellerey, G. Favennec, V. Lanfranchi, et al. Active reduction of electrical machines magnetic noise by the control of low frequency current harmonics, in: IECON 2012, Montreal, Oct. 25-28, 2012, pp.1 654-1659.

[27] H. Wu, D. Depernet, V. Lanfranchi. Comparison of torque ripple reductions and copper losses of thre e synchronous reluctance machines. In: VPPC 2017, Belfort, France Dec. 11-14, 2017. 